\title{
Trade-off between urgency and reduced editorial capacity affect publication speed in ecological and medical journals during 2020
}

\author{
Lucas Rodriguez Forti (iD ${ }^{1 凶}$, Luiz A. Solino ${ }^{2,3}$ \& Judit K. Szabo ${ }^{1,4}$
}

While the speed of publication in academic journals has decreased over time, delays in the review process can still cause frustration and damage the authors' career. During the COVID19 lockdown, scientists struggled to manage tasks and academic journals announced possible publication delays due to reduced editorial capacity. In this context, COVID-19 research has been somewhat paradoxical, due to societal and editorial pressures for fast publication. We hypothesised that given the urgency of disseminating pandemic-related information, articles on the topic would be published as a priority in 2020. We analysed the submission-topublication time lag for 5790 articles published between January 1, 2018 and December 31, 2020 in eight ecology and eight medical journals. We also analysed patterns in the gender of first and last authors. All 16 journals were international, with relatively high impact factor (between 2.34 and 36.13) and partially or fully open access. Even though articles in general took longer to get published, the speed of publication increased in 2020, as the faster review of 419 COVID-19 articles compensated for the longer submission-to-publication time lag of non-COVID-19 publications. Manuscripts in journals with a higher impact factor and only partial open access took longer to get published during the last three years. In 2020, the ratio of articles with male and female first and last authors remained similar to that in 2019, maintaining the gender bias in scientific productivity. Female scientists, especially when they are providing maternity and other primary care, need more support for their careers, such as relief from teaching duties and adjustments on assessment criteria to access research funding. We advocate that topics besides COVID-19, particularly those that could help to solve other urgent crises, should also benefit from faster publication.

\footnotetext{
${ }^{1}$ Instituto de Biologia, Universidade Federal da Bahia, Rua Barão de Jeremoabo, 668 - Campus de Ondina, Salvador, Bahia 40170-115, Brazil. ${ }^{2}$ Secretaria de Estado de Educação de Mato Grosso, Rua Engenheiro Edgar Prado Arze, Quadra 01, Lote 05, Setor A - Centro Político Administrativo, Cuiabá, MT 78049906, Brazil. ${ }^{3}$ Fundação Ecotrópica, Rua 03, 391, Boa Esperança, Cuiabá, MT 78068-375, Brazil. ${ }^{4}$ College of Engineering, IT and Environment, Charles Darwin

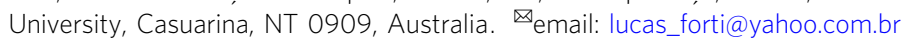




\section{Background}

ublication delays frustrate scientists who wait for months or even years until they see their manuscripts published (Nguyen et al., 2015). Repeated delays can trigger anxiety and depression in authors, make them withdraw the publication or turn to predatory journals that can deliver at shorter time frames (Kurt, 2018). Unfortunately, the academic community is ruled by the "publish or perish" pressure, and with manuscripts trapped in the journals' review systems, these delays can affect the career of scientists by costing them promotions, grants and collaborations (Nguyen et al., 2015).

Publishing delays not only affect the academic career of the authors, but also halt and impair decision-making, and delay finding solutions to important problems in different societal spheres (Björk and Solomon, 2013). For instance, in the case of a novel disease, the sooner an effective treatment or prevention method reaches the medical community, the more lives can be saved. For this reason, the cost of legitimate time restraints or procrastination by actors (authors, editors and reviewers) involved in the revision process is often too high to pay and many authors choose preprint platforms to get their work disseminated earlier or to get reviewed by a larger community of readers (Kaiser, 2017; Johansson et al., 2018; Mercier et al., 2020).

While temporal trends in the submission-to-publication time lag vary depending on the scientific area (Björk and Solomon, 2013; Huisman and Smits, 2017), academic publication has generally became slower in the past few decades (Ellison, 2002; Alberts et al., 2008; Tort et al., 2012), possibly as a result of more rounds of reviews (Ellison, 2002). On the other hand, the emergence of online publication, where journals often do not designate individual articles into volumes and issues, has somewhat sped up submission-to-publication times (Tort et al., 2012).

Different journals have different editorial capacities, quantity, types and length of articles published, policy and deadlines for peerreview, but their impact factor still seems to lead to faster publication (Huisman and Smits, 2017; Tort et al., 2012). Within journals, delays may be due to the quality of manuscripts, the time editors spend to find available reviewers, the time reviewers take to return the review (Lotriet, 2012), and the time the authors need to resubmit their revised manuscript (Björk and Solomon, 2013). Delays can also emerge in the production stage, i.e., the time taken to publish an article after it has gone through the peer-review process and has been accepted (Yu et al., 2005; Luwel et al., 2020).

Nevertheless, since early 2020, the submission-to-publication time lag has been affected by a new factor, the COVID-19 pandemic (Horbach, 2020). The COVID-19 pandemic has affected the health of over a hundred million people and caused a global financial crisis perceivable already in 2020 (Mofijur et al., 2021). This year was also atypical for scientific research and publication (Stokstad, 2020). Among other activities, lockdowns have delayed or cancelled laboratory-based activities, as well as fieldwork, travel, workshops, conferences and other large meetings (Corlett et al., 2020; Pennisi, 2020). With the collapse of public health systems around the world, many medical scientists focused all their efforts on combating the disease at the frontlines (Eisen et al., 2020). Primary carers (Myers et al., 2020) and early-career researchers (Ahmed et al., 2020) in particular found it more difficult to keep up with the workload under these conditions. While female scientists have been reported to be more negatively affected in general (Myers et al., 2020), as well as in the medical field (Viglione, 2020), the proportion of female authors who published in ecology journals did not decrease at the beginning of the pandemic (Fox and Meyer, 2021), potentially as the effects of the pandemic were not yet observable.

Not being able to conduct fieldwork or new laboratory experiments, many scientists have focused on writing up and submitting research they have conducted previously. The situation has also inspired an unprecedented number of scientific publications that focused on different aspects of the pandemic itself, including actual and potential impacts (close to 100,000 with the topic "COVID-19" according to the Scopus database on February 09, 2021). Nevertheless, in 2020, many authors received the automated reply from journals upon submission: "We are experiencing a higher volume of manuscript being submitted while operating under reduced editorial capacity due to restrictions in place as a result of COVID-19, therefore it may take slightly longer to move papers through the system". Thus, while eager to fulfil society's thirst for new information with regard to the pandemic, we are facing new obstacles that can increase manuscript processing time by editors and reviewers for articles not strictly relevant to COVID-19.

While based on anecdotal data and the personal experience of the authors it seemed like processing times (submission-to-publication time lags) for the submitted manuscripts have increased considerably, we wanted to test this formally. Our central question was whether the pandemic has changed submission-topublication times in 2020 compared to the previous two years. We also wanted to test if these changes in time lags were similar for studies explicitly mentioning COVID-19 in the title or the abstract compared to other topics in both medical and ecological publications. We hypothesised that in 2020 the time between submission and publication of an article would be longer compared to the two previous years. However, we predicted that this pattern would not hold for publications about COVID-19, which were under societal (and editorial) pressure for faster progress.

Considering that the lockdown did not affect all scientists equally, we also addressed some complementary questions: Did the discipline of the journal (ecology or medicine), the number of authors and the number of pages of the article affect the submission-to-revision time lag in the 16 journals we evaluated? Has the pandemic affected the proportion of articles with male and female first and last authors in ecology and medical journals? And finally, was the impact factor of journals correlated to the average submission-to-publication time lag? The responses to these questions can help us gain an insight into the complex effects of the pandemic on academic publishing during the first year when large changes in social structure occurred.

\section{Methods}

Data collection. We selected 16 high-impact journals, eight from medicine and eight from ecology (Table S1). We selected journals that were partially or fully open access with relatively high impact factors (between 2.34 and 36.13) that we assumed represented publication trends in their fields. Being limited to open access journals restricted the number of journals analysed, as often we needed to open the pdfs of the articles to obtain the dates when the manuscripts were received, reviewed and published. We manually accessed articles on the webpage of each journal and analysed 5790 review and research articles published between the first issue of 2018 up to articles early online on December 31, 2020. For journals with less than 120 articles per year, we considered all qualifying articles. For other journals, we randomly selected an equal number of articles within each issue to add up to 120 articles per year. Based on the title, we categorised whether the article was relevant to some aspects of the COVID-19 pandemic. When the topic was not clear based on the title, we read the abstract of the article. Articles were considered as related to COVID-19 when the words "COVID-19", "SARSCOV2", "pandemic" or "lockdown" were mentioned in the title or in the abstract in relation to the COVID-19 pandemic. From each article, we obtained the Digital Object Identifier, the number of 
Table 1 Results of the three fitted generalised linear mixed models with journals as random effect.

\begin{tabular}{|c|c|c|c|}
\hline & Models & & \\
\hline Summary results & $\begin{array}{l}\text { Log(timelag) year }+ \\
(1 \mid \text { journal })\end{array}$ & $\begin{array}{l}\text { Log(timelag_non_covid }) \sim \text { year }+ \\
(1 \mid \text { journal })\end{array}$ & $\begin{array}{l}\text { Log(timelag_rev) } ~ \\
\text { covid + discipline + authors + pages + }(1 \mid \text { journal })\end{array}$ \\
\hline Number of articles & 5787 & 5368 & 1363 \\
\hline Intercept & $\begin{array}{l}\text { Estimate }=5.158 ; \mathrm{Cl}[5.011 \\
5.305] t \text {-value }=70.880 \\
p<0.001\end{array}$ & $\begin{array}{l}\text { Estimate }=5.123 ; \mathrm{Cl}[4.989,5.255] \\
t \text {-value }=77.618 ; p<0.001\end{array}$ & $\begin{array}{l}\text { Estimate }=3.882 ; \mathrm{Cl}[3.522,4.226] t \text {-value }=20.592 ; \\
p<0.001\end{array}$ \\
\hline Fixed effect (2019) & $\begin{array}{l}\text { Estimate }=-0.011 ; \mathrm{Cl}[-0.044 \\
0.023] t \text {-value }=-0.607 \\
p=0.544\end{array}$ & $\begin{array}{l}\text { Estimate }=0.014 ; \mathrm{Cl}[-0.016 \\
0.044] \text {-value }=0.884 ; p=0.376\end{array}$ & Not applicable \\
\hline $\begin{array}{l}\text { Fixed effect } \\
\text { (COVID-19) }\end{array}$ & Not applicable & Not applicable & $\begin{array}{l}\text { Estimate }=-0.176 ; \mathrm{Cl}[-0.668,-0.462] \\
t \text {-value }=-10.755 ; p<0.001\end{array}$ \\
\hline $\begin{array}{l}\text { Fixed effect } \\
\text { (Number of pages) }\end{array}$ & Not applicable & Not applicable & $\begin{array}{l}\text { Estimate }=0.006 ; \mathrm{Cl}[-0.001,0.014] t \text {-value }=1.457 \\
p=0.1453\end{array}$ \\
\hline
\end{tabular}

authors, the name of the first and last authors (NA for last author if the publication had only one author), date of submission, date of revision (if applicable), and the date the manuscript was accepted and published. Based on Julian dates, we calculated the number of days between the date of submission and revision (i.e., the submission-to-revision time lag), between the date of submission and acceptance (submission-to-acceptance time lag) and between the date of submission and publication (submission-to-publication time lag). We used "NA" in our dataset to identify publications with missing data in any of these fields, which were excluded from data analysis. As some journals have an earlier date for first published online than the date of the printed issue (online-to-print publication lag), we used the date of the article appearing first online when calculating submission-to-publication time in order to standardise sampling. We identified the gender of the authors searching publicly available data on the internet based on the name and the institution of the researcher (institution homepage, Research Gate, Google Scholar, LinkedIn, etc.) looking for pictures, pronouns and other information referring to the researcher.

Data analysis. To test if the pandemic altered publication speed in 2020, we compared the submission-to-publication time lag (response variable) among volumes published in 2018, 2019 and 2020 through a generalised linear mixed model (GLMM), with the journal as a random factor and year as fixed factor (predictor variable) using the equation: "log(timelag) year+(1 | journal)". We also ran the GLMM only for non-COVID-19 articles in order to detect the effect of pandemic on submission-to-publication time lag in the absence of COVID-19 articles. Since time lags are discrete data, we logtransformed these values to achieve normal distribution. We used the lmerTest (Kuznetsova et al., 2017) and lme4 (Bates et al., 2015) packages in R version 4.0.2 (R Core Development Team, 2020).

Given the pressures for a fast review, we also tested the effect of the publication topic (COVID-19 or not) on submission-torevision time (response variable). We applied a GLMM to the logtransformed response variable and we used journal as random factor and discipline (ecology or medicine), number of authors and number of pages as fixed factors (predictors), as we found no correlation between these additional fixed factors. In this GLMM we used the following equation: " $\operatorname{lmer}(\log ($ timelag_review) $\sim$ covid + area + authors + pages +(1|journal)".

For all GLMM models, we verified the normality of the residues graphically using the qqnorm and qqline functions in $\mathrm{R}$. After running the models, we checked the maximum residual likelihood values, the estimates for each fixed effect (effect size), as well as their $p$-values individually, to explain the variation of the residuals. We also calculated the $95 \%$ confidence interval using 1000 bootstrap iterations as a validation for each estimate with the confint.merMod function of the lme4 package (Bates et al., 2015). CIs also indicate the precision around the model estimated parameter (Nakagawa and Innes, 2007).

To test whether the productivity of female lead authors decreased during the pandemic, we compared the proportion of genders of the first and last authors for 2019 and 2020. We treated publications in ecology and medicine separately and carried out a Fisher's exact test with $95 \%$ of confidence interval using the fisher.test function in $\mathrm{R}$.

Finally, we correlated journal impact factor with the average and standard deviation of the submission-to-publication time of the same journal through Pearson correlations using the functions cor, and cor.test in R.

\section{Results}

Analysing publications between January 1, 2018 and December 31,2020 , we found that the average submission-to-publication time was shorter in 2020 than in 2018 and $2019(n=5787$; model estimate for $2020=-0.148$ with $95 \%$ CI $[-0.181,-0.116]$; $t$ value $=-9.001 ; p<0.001$; Table 1$)$. Nine of the 16 analysed journals had shorter submission-to-publication time lags in 2020 , and it took longer to publish in 2019 than in 2018 in eight journals (Table 2). Five journals presented multimodal distribution curves with regard to the submission-to-publication time lag in 2020 (Fig. 1).

Even though in general it was faster to publish in 2020, the submission-to-publication time lag was longer in 2020 for nonCOVID-19 articles than in the previous two years $(n=5368$; model 


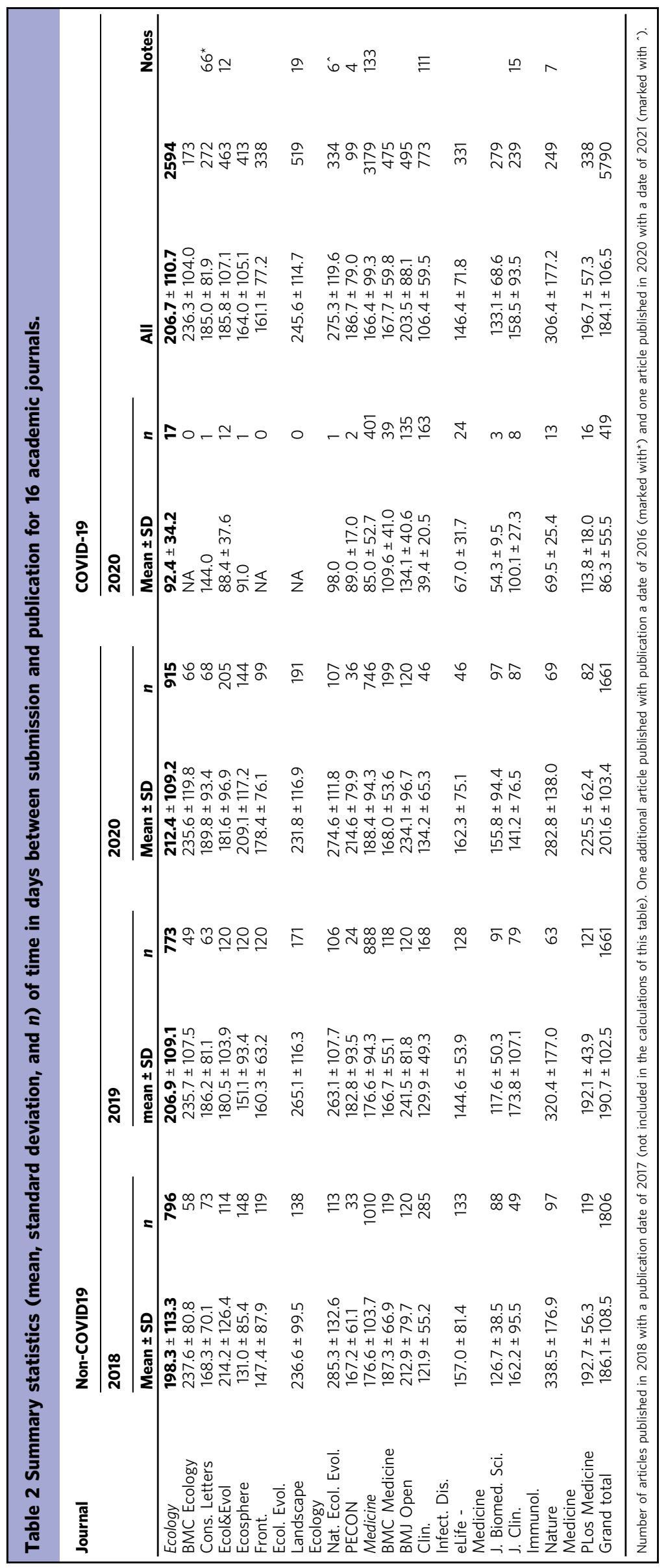




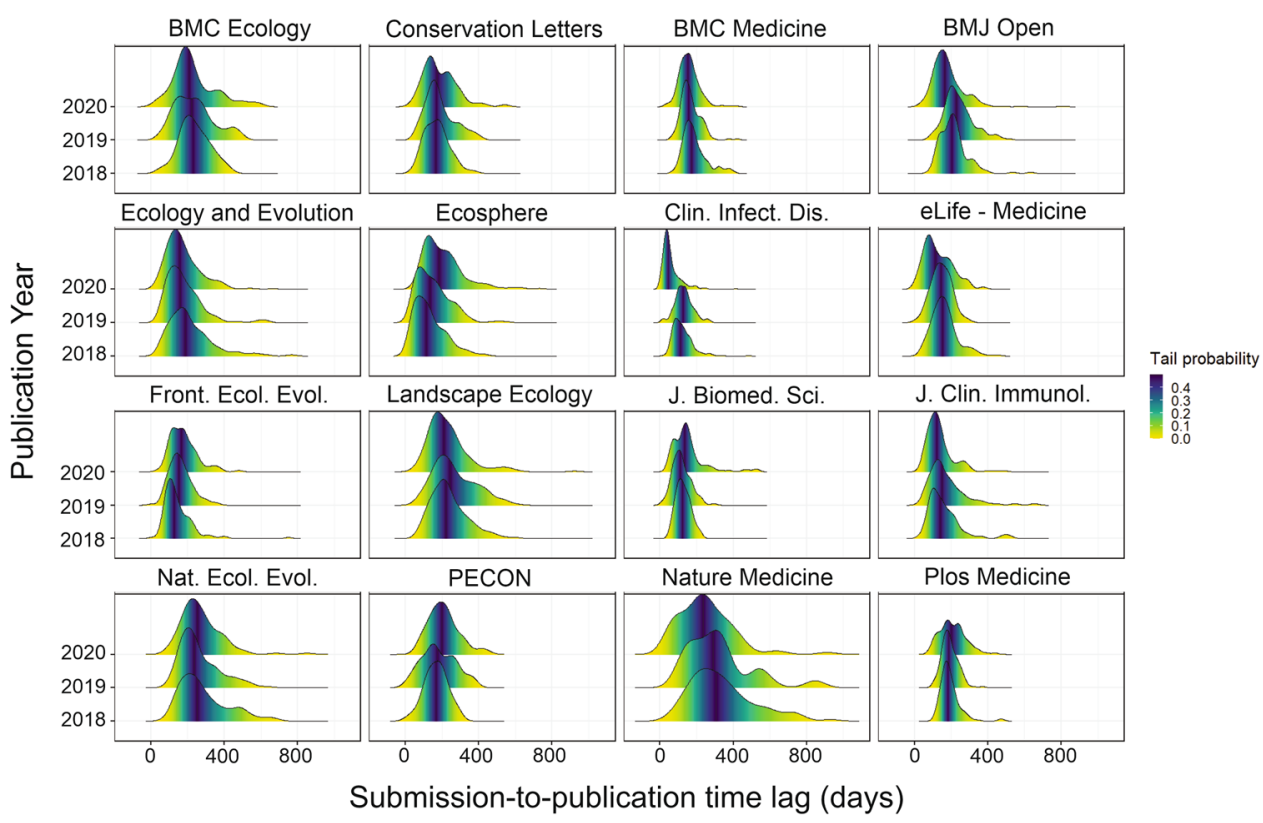

Fig. 1 Density curves of submission-to-publication time in 2018-2020 for 16 academic journals. Ecology journals are on the left, medical journals on the right. Colours represent the probability distribution.

estimate for $2020=0.032$ with $95 \%$ CI $[0.024,0.086] ; t$ value $=3.479 ; P<0.001$; Table 1 ). This increasing trend in 2020 was driven by exceptionally long publication delays (i.e., up to 912 days). Non-COVID-19 articles took longer to publish in 2020 than in 2019 in 11 journals (69\% of the analysed journals; Table 2).

The topic "COVID-19" decreased the length of the reviewing process $(n=1363$; model estimate $=-0.176$ with $95 \%$ CI $[-0.668$, $-0.462] ; \quad t$-value $=-10.755 ; \quad P<0.001$; Table 1$)$. We backtransformed the estimates for easier interpretation and found that it takes on average 31 days less (CI $[-39,-23])$ to publish an article about COVID-19 compared to other topics. Interestingly, all COVID-19 articles were published faster than the journals' average (Fig. 2). The model detected that the number of authors slightly increased the submission-to-revision time lag $(n=1363$; model estimate $=0.007$ with $95 \%$ CI $[0.0003,0.0131]$; $t$-value $=2.091 ; P<0.001)$, while the discipline and the number of pages had no effect. Articles published in 2018 and 2019 had an average submission-to-revision time of $150 \pm 90(n=1898)$ and $169 \pm 112(n=1569)$ days for medicine and ecology, respectively. COVID-19 articles had $72 \pm 46(n=402)$ and $55 \pm 31(n=17)$ days for the reviewing process for medicine and ecology, respectively. In fact, one COVID-19 article was accepted within a day and another 15 articles within a week of submission to medical journals. For ecology journals, the fastest acceptance of a COVID-19 article was nine days.

Even though COVID-19 was a topic relevant enough to be published in ecology journals, we only found 17 publications in this period in the sampled ecology journals. This, in fact is a major limitation of our dataset based on the small contribution of samples coming from ecology journals and also because of the high variability (66\%) among observations of the submission-to-revision time lag.

We also tested if the pandemic affected the ratio of female and male lead authors during 2020. In general, the ratio of publications with male and female leads (both first and last authors) in 2020 was similar to that in 2019 in both ecology and medicine (Table S2, Fig. 3). The number of publications of different first-last author gender combinations remained similar between the years in medical journals. For ecology, the number of articles with the female-female lead combination increased and male-female lead combination decreased in 2020 (Fig. 4). The most frequent author combination for both ecology and medical journals was male-male, while for medical journals male-female was the least frequent first-last author combination for all 3 years. In ecology, in 2020 the least frequent combination was male-female, while in earlier years, female-female combination was the least common. Among the 419 COVID-19 articles (ecology and medical journals together), 26.4\% had female first author and male last author, $21.2 \%$ had male first author and female last author, and only $14.2 \%$ had both leads female.

Among medical journals, Clinical Infectious Diseases had the fastest submission-to-publication time (106.3 \pm 59.4 days $)$ and Nature Medicine had the slowest (306.4 \pm 177.2 days). Among ecology journals, Frontiers in Ecology and Evolution was the fastest $(161 \pm 77.1$ days) and Nature Ecology and Evolution the slowest (275.3 \pm 119.5 days). While there were more COVID-19 articles published in medicine than in ecology (402 and 17, respectively), not all medical journals had faster submission-to-publication times compared to ecology journals (Fig. 5). We found positive correlations between a journal's impact factor and the average $(n=16$; $r=0.563 ; P<0.05)$ and standard deviation $(n=16 ; r=0.633$; $P<0.01)$ of their submission-to-publication time.

\section{Discussion}

In 2020, a new factor, the topic of COVID-19 appeared, which had a large effect on the submission-to-publication time of journals (Horbach, 2020). The pandemic did not only cause the "covidisation" of scientific publication (Pai, 2020), but also affected publication speed in an unbalanced way in both ecology and medicine. We suspect that the multimodal distribution of the submission-to-publication times in 2020 that were observed in five journals, was an artefact of the faster processing time of COVID-19 articles, while manuscripts on other topics took longer. These results were already detectable in April 2020 among medical journals (Horbach, 2020), indicating the prioritisation of COVID-19 manuscripts by editors. According to our results, some articles were published within a few days after submission, demonstrating the fast-tracking of articles relevant to this public health emergency. Other studies reported COVID-19 articles accepted in a median time of under seven days (Kun, 2020; 


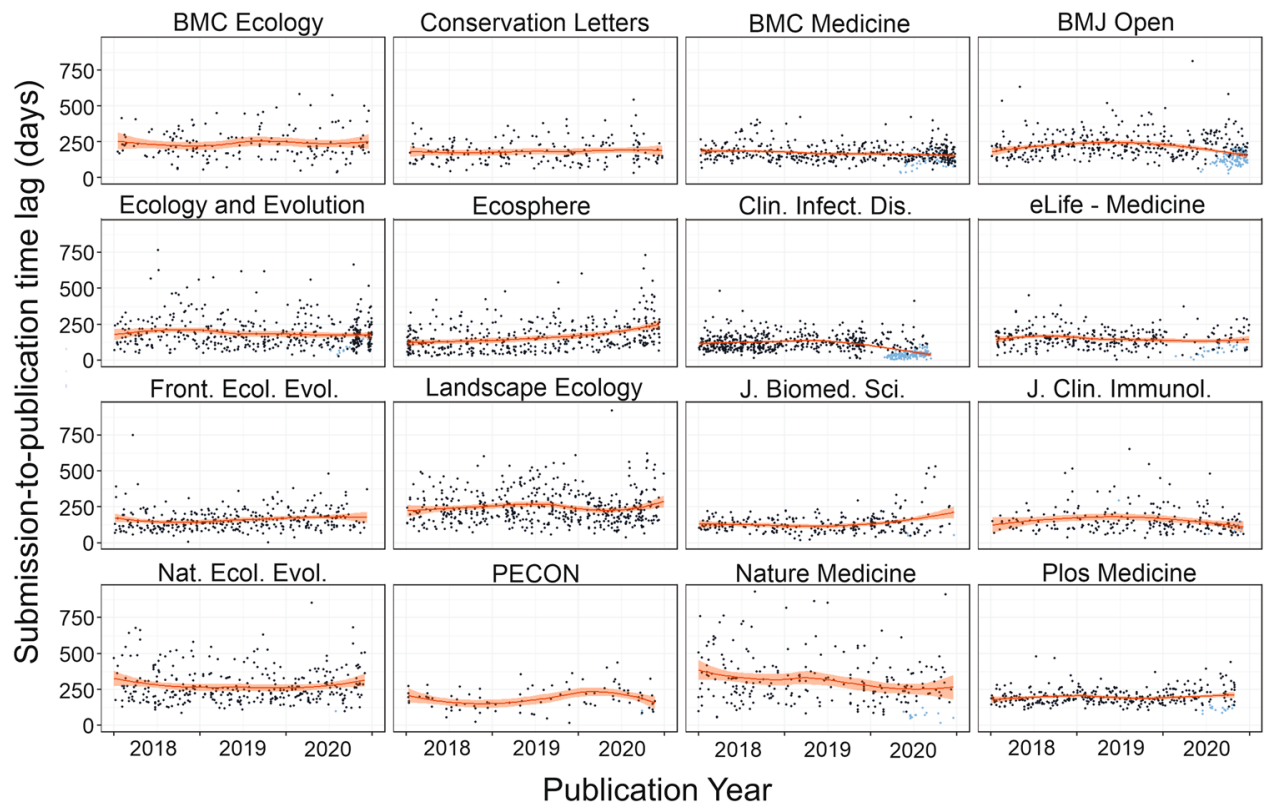

Fig. 2 Distribution of submission-to-publication time in 2018-2020 for 16 academic journals. Ecology journals are on the left and medical journals on the right. Light blue dots represent COVID-19 publications and red lines show the trend based on a non-linear regression model.
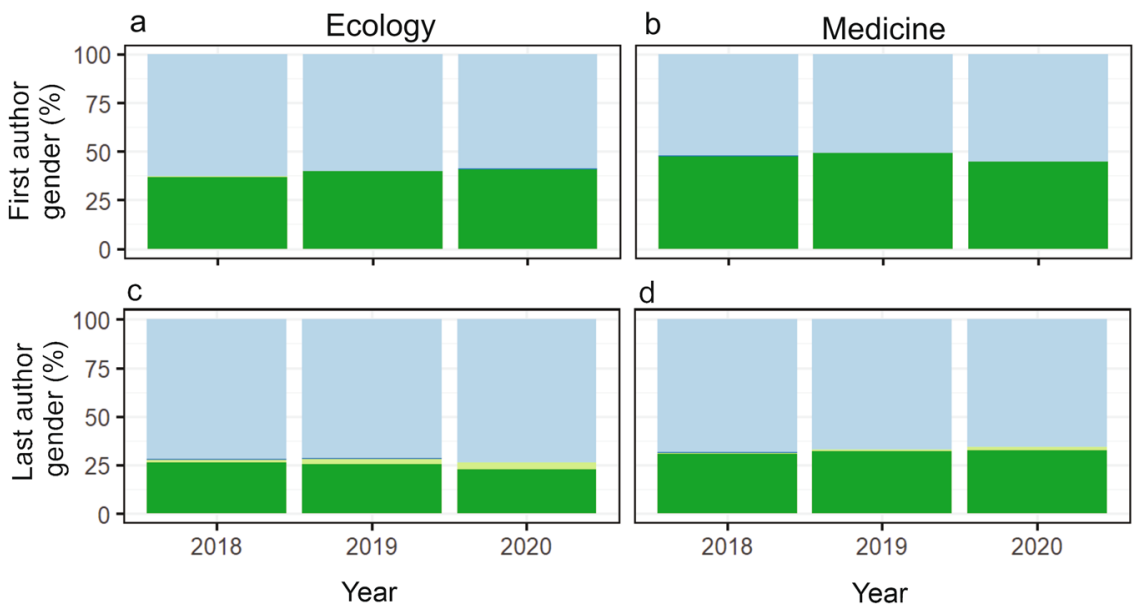

Fig. 3 The proportion of publications among lead (first and last) authors of different genders in ecology and medical journals in 2018-2020. a First authors in ecology, $\mathbf{b}$ first authors in medicine, $\mathbf{c}$ last authors in ecology, and $\mathbf{d}$ last authors in medicine. Blue shading represents male, green represents female and light green are authors of unidentified gender. The one (self-identified) transgender last author in ecology in 2018 is shown in dark blue.

Palayew et al., 2020), which is usually characteristic of predatory journals (Beall, 2012). This astonishing speed of manuscript management by journals that usually take months to publish articles have raised questions about the quality of the reviewing process (Palayew et al., 2020; Benjamens et al., 2021). In fact, there have been a higher number of retractions with regard to the COVID-19 literature (da Silva et al., 2021) and some authors advocate that increasing journals efficiency to reduce publication delays would facilitate the publication of lower-quality research (Tiokhin et al., 2021). However, while many submitting authors understand that high-quality peer-review takes time, we know that if manuscripts reach the right reviewers in a timely manner and are prioritised by them, in extreme cases they can be reviewed in a couple of days. Realistically, manuscripts can spend weeks (or months) in the drawer of an editor or a reviewer (Ware and Mabe, 2015), often because of competing priorities.

The fast speed of publishing articles about COVID-19 has proven that journals are able to process articles rapidly even under the unusual working conditions of the lockdown. While the urgency of publishing COVID-19 articles is understandable, many other topics, such as publications that offer solutions to the biodiversity crisis (Kareiva et al., 2002) and urgent issues with regard to public health and economy (Björk and Solomon, 2013) also need and deserve faster editorial services. Articles are often published on preprint servers, but the reliability of the information on these platforms has also been questioned (Kaiser, 2017). The mechanisms affecting the length of the review process are known to be idiosyncratic and often include the low responsiveness of reviewers and editors (Huisman and Smits, 2017). Surprisingly, in 2020, reviewers of ecology journals replied to invitations to review and returned their reviews more rapidly than previously (Fox and Meyer, 2021), which contrast with our results for non-COVID-19 articles. The results by Fox and Meyer (2021) need to be interpreted with caution, as they are based on data of only the first five months of the pandemic. An alternative explanation can be that the cancellation of fieldwork and the interruption of teaching tasks made reviewers more available to review for these journals. We also found that the more authors a manuscript had, the more time the review process took, possibly as 


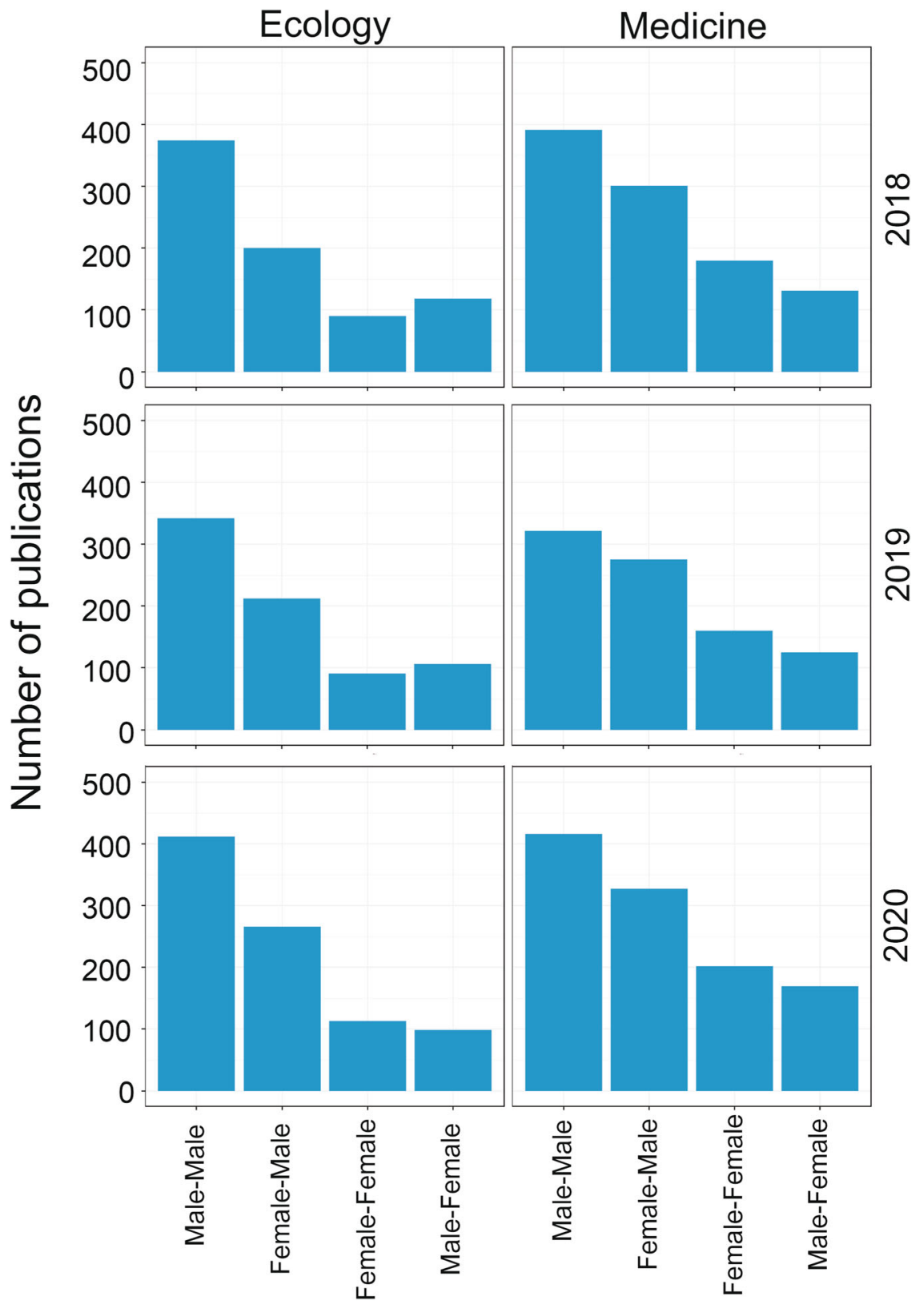

Fig. 4 Absolute number of publications among different first-last author combinations in ecology and medical journals in 2018-2020. Transgender authors and those of unidentified gender are not shown.

such manuscripts take longer to be checked by all authors before resubmission. Submission-to-publication time may also depend on journal performance and features, such as being open access or early online availability (Björk and Solomon, 2013; Sebo et al., 2019). Coincidentally, the three slowest journals in our study are considered "hybrid open access" (European Union, 2021). To our surprise, publication time was positively correlated with the journals' impact factor, partially contradicting an earlier study (Huisman and Smits, 2017), which found highly ranked journals having faster submissionto-revision times among accepted articles.

Regardless of the journal, the pandemic likely hampered the progress of female main authors in 2020, maintaining the existing gender bias (Santos et al., 2019; Filardo et al., 2016). This result is similar to the findings of a previous analysis of six ecology journals until October, 2020 (Fox and Meyer, 2021). The magnitude of gender bias varies among areas of study and countries (Salerno et al., 2020; de Kleijn et al., 2020). Female are often proportionally less common as lead authors than males (de Kleijn et al., 2020; Eigenberg and Whalley, 2015; de Camargo and Hayashi, 2017). Furthermore, articles written by female leads seem to receive fewer citations, possibly as a result of fewer international collaborations compared to male scientists (Larivière et al., 2013). A study analysing publications between January 1 and June 5, 2020, found that the number of articles with female first authors was 19\% lower for COVID-19 articles compared to articles published in the same medical journals in 2019 (Andersen et al., 2020; Viglione, 2020). Domestic and other tasks, particularly for female scientists who are often primary carers, have diminished the time available for the production of articles, potentially exacerbating the gender gap among main authors in 2020 (Collins et al., 2021; Squazzoni et al., 2020; Cui et al., 2021). Determining the reasons for this gender gap in academic productivity in science continues to be a complex task (Larivière et al., 2013). Although peer review and editorial processes in general do not seem to influence decisions for manuscripts written by female authors 


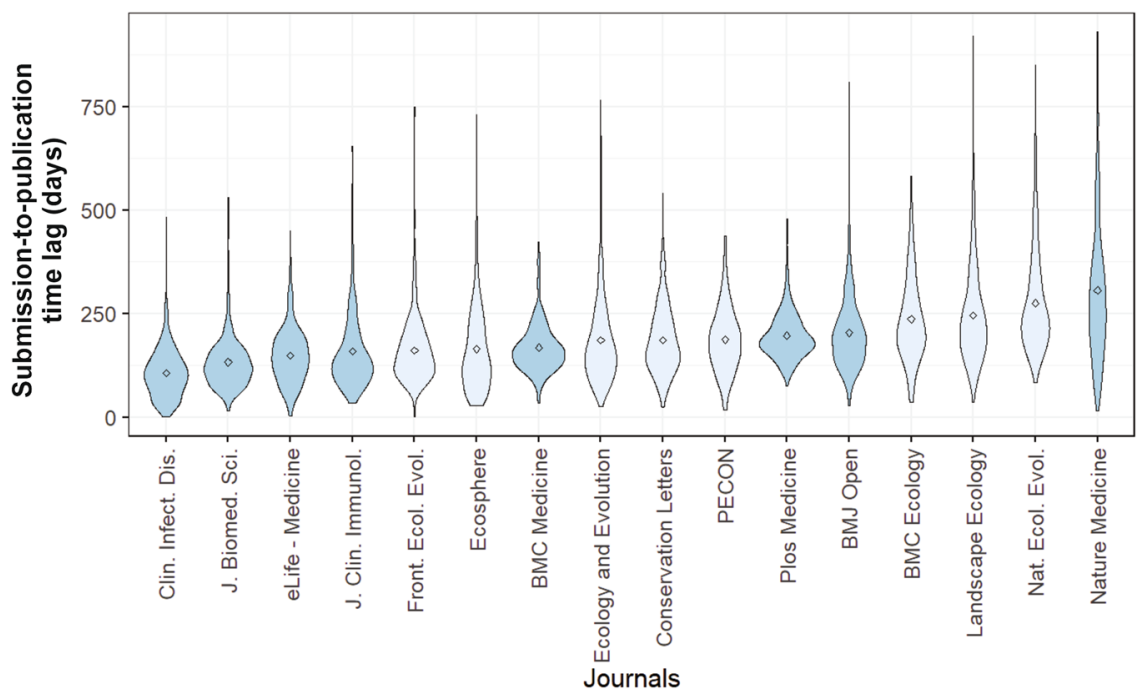

Fig. 5 Average submission-to-publication time lag among 16 academic journals in order of increasing mean values from left to right. Ecology journals are indicated by light blue and medical journals by dark blue.

(Squazzoni et al., 2021), the academic community needs to find ways to equalise this gender inequality. Actions could be taken for a higher gender diversity among editors of high-impact journals and to provide better support to female scientists, including allowing more time for article resubmission. Younger female scientists should be invited more often to review manuscripts, giving them an opportunity to improve their writing skills (Lerback and Hanson, 2017). Also, as a systematic solution, female faculty could receive more teaching support or full relief from teaching duties, better support for childcare, and adjusted assessment criteria for candidates for research funding and tenured positions (Andersen et al., 2020).

For future work, it would be interesting to look at a more nuanced analysis using questionnaires with regard to regional, socioeconomic and temporal patterns with regard to research and publication productivity of authors, reviewers and editors. Journals could also facilitate the analysis of publication data by making metadata more accessible for instance, via API. As we have collected data manually from each article, we might have inadvertently introduced errors, but we believe these to be non-directional. Similarly, the three authors made a one-by-one decision for each article with regard to dealing with COVID-19, discussing the few non-obvious cases, which hopefully minimised the number of false-negatives and false positives.

Our work highlights the effects of the pandemic on the speed of scientific publication in 16 academic journals in medicine and ecology and shows a strong prioritisation of COVID-19 articles in these two disciplines, despite the limited number (17) of COVID-19 articles in ecology journals. We assume that pandemic-related publications were considered special, attracting the interest of the readers among journals of both disciplines. Ecology journals, for example, published COVID-19 research about the effects of pandemic on distance education (Corlett et al., 2020), discussed the "anthropause" with regard to air pollution (Wang et al. 2020), populations of animals in their natural habitat (Rutz et al., 2020) and in cities (Vardi et al., 2021), or the effects of lockdown on animal trade and wildlife diseases (Forti et al., 2020). However, our results should be interpreted with caution given the small sample size of COVID-19 articles we found in the eight ecological journals. In addition, the high variability on the submission-to-revision time lags indicates that more data (when they become available in the future) can possibly improve the model estimate.

The temporal advantages to publish COVID-19 articles seem to attract authors to the subject, presumably temporarily taking priority over other important topics with public health relevance. The possible uniformisation of science may somewhat threaten the resolution of other crises dependent on scientific data (Pai, 2020). We also suggest additional actions to reduce the gender gap in productivity, which has been further exacerbated by the pandemic, in order to provide more equal scientific production. Finally, similar to articles on COVID-19, decreasing the submission-to-publication time lag for all articles can reduce the frustration of the submitting authors, minimise the damage to their career by not submitting them to unnecessary delays, and also disseminate knowledge faster on urgent matters.

\section{Data and materials availability}

Data can be accessed at https://doi.org/10.5281/zenodo.4446285.

Received: 9 February 2021; Accepted: 4 October 2021;

Published online: 15 October 2021

\section{References}

Ahmed M, Arslan AH, Behbahani AB, Charpentier CJ, Morais LH, Mallory S, Pool A-H (2020) The precarious position of postdocs during COVID-19. Science 368:957-958

Alberts B, Hanson B, Kelner KL (2008) Reviewing peer review. Science 321:15

Andersen JP, Nielsen MW, Simone NL, Lewiss RE, Jagsi R (2020) COVID-19 medical papers have fewer women first authors than expected. eLife 9:e58807

Bates DM, Maechler M, Bolker BM, Walker S (2015) Fitting linear mixed-effects models using lme4. J Stat Softw 67:1-48

Beall J (2012) Predatory publishers are corrupting open access. Nat News 489:179

Benjamens S, Pol RA, de Meijer VE, Haring MP (2021) Peer review during demanding times: maintain rigorous standards. Scientometrics 126:6115-6117

Björk B-C, Solomon D (2013) The publishing delay in scholarly peer-reviewed journals. J Informetr 7:914-923

Collins C, Landivar LC, Ruppanner L, Scarborough WJ (2021) COVID-19 and the gender gap in work hours. Gend Work Organ 28:101-112

Corlett RT, Richard BP, Devictor V, Maas B, Goswam VR, Bates AE, Pin Koh Lian, Regan TJ, Loyola R, Pakeman RJ, Cumming GS, Pidgeon AM, Johns D, Roth $\mathrm{R}$ (2020) Impacts of the coronavirus pandemic on biodiversity conservation. Biol Conserv 246:108571

Cui R, Ding H, Zhu F (2021) Gender inequality in research productivity during the COVID-19 pandemic. Manuf Serv Oper Manag. https://doi.org/10.1287/ msom.2021.0991

da Silva JAT, Bornemann-Cimenti H, Tsigaris P (2021) Optimizing peer review to minimize the risk of retracting COVID-19-related literature. Med Health Care Philos 24:1-6 
de Camargo JRF, Hayashi MCP (2017) Coautoria e participação feminina em periódicos brasileiros da área de cirurgia: estudo bibliométrico. Rev Digit Bibliotecon Ciênc Inf 15:148-170

de Kleijn M, Jayabalasingham B, Falk-Krzesinski HJ, Collins T, Kuiper-Hoyng I, Cingolani I, Zhang J, Roberge G, et al (2020) The researcher journey through a gender lens: an examination of research participation. Career progression and perceptions across the globe. https://www.elsevier.com/connect/gender-report

Eigenberg HM, Whalley E (2015) Gender and publication patterns: Female authorship is increasing, but is there gender parity? Women Criminal Justice 25:130-144

Eisen MB, Akhmanova A, Behrens TE, Weigel D (2020) Publishing in the time of COVID-19. eLife 9:e57162

Ellison G (2002) The slowdown of the economics publishing process. J Political Econ 110:947-993

European Union (2021) https://ec.europa.eu/info/research-and-innovation/strategy/ goals-research-and-innovation-policy/open-science/open-science-monitor/trendsopen-access-publications_en. Accessed 27 Jan 2021

Filardo G, da Graca B, Sass DM, Pollock BD, Smith EB, Martinez MAM (2016) Trends and comparison of female first authorship in high impact medical journals: observational study (1994-2014). BMJ 352:i847

Forti LR, Japyassú HF, Bosch J, Szabo JK (2020) Ecological inheritance for a post COVID-19 world. Biodivers Conserv 29:3491-3494

Fox CW, Meyer JA (2021) The influence of the global COVID-19 pandemic on manuscript submissions and editor and reviewer performance at six ecology journals. Funct Ecol 35:4-10

Horbach SPJM (2020) Pandemic publishing: medical journals strongly speed up their publication process for COVID-19. Quant Sci Stud 1:1056-1067

Huisman J, Smits J (2017) Duration and quality of the peer review process: the author's perspective. Scientometrics 113:633-650

Johansson MA, Reich NG, Meyers LA, Lipsitch M (2018) Preprints: an underutilized mechanism to accelerate outbreak science. PLoS Med 15:e1002549

Kaiser J (2017) The preprint dilemma. Science 357:1344-1349

Kareiva PM, Marvier M, West S, Hornisher J (2002) Slow-moving journals hinder conservation efforts. Nature 420:15

Kun Á (2020) Time to acceptance of 3 days for papers about COVID-19. Publications 8:30

Kurt S (2018) Why do authors publish in predatory journals? Learn Publ 31:141-147

Kuznetsova A, Brockhoff PB, Christensen RHB (2017) lmerTest package: tests in linear mixed effects models. J Stat Softw 82:1-26

Larivière V, Ni C, Gingras Y, Cronin B, Sugimoto CR (2013) Bibliometrics: Global gender disparities in science. Nat News 504:211

Lerback J, Hanson B (2017) Journals invite too few women to referee. Nat News 541:455

Lotriet CJ (2012) Reviewing the review process: Identifying sources of delay. Australas Med J 5:26-29

Luwel M, van Eck NJ, van Leeuwen T (2020) Characteristics of publication delays over the period 2000-2016. In: Daraio C., Glänzel W. (eds) Evaluative informetrics: the art of metrics-based research assessment. Springer. Cham

Mercier M, Magloire V, Karnani M (2020) Enhancing scientific dissemination in neuroscience via preprint peer-review:"Peer Community In Circuit Neuroscience. Neuroanat Behav 2:e9

Mofijur M, Rizwanul Fattah LM, Alam MdAsraful, Saiful Islam ABM, Ong HC, Ashrafur Rahman SM, Najafi G, Ahmed SF, Uddin MdAlhaz, Mahlia. TMI (2021) Impact of COVID-19 on the social, economic, environmental and energy domains: lessons learnt from a global pandemic. Sustain Prod Consum 26:343-359

Myers KR, Tham WY, Yin Y, Cohodes N, Thursby JG, Thursby MC, Schiffer P, Walsh JT, Lakhani KR, Wang D (2020) Unequal effects of the COVID-19 pandemic on scientists. Nat Hum Behav 4:880-883

Nakagawa S, Cuthill IC (2007) Effect size, confidence interval and statistical significance: a practical guide for biologists. Biol Rev 82:591-605

Nguyen VM, Haddaway NR, Gutowsky LFG, Wilson ADM, Gallagher AustinJ, Donaldson MR, Hammerschlag N, Cooke SJ (2015) How long is too long in contemporary peer review? Perspectives from authors publishing in conservation biology journals. PLoS ONE 10:e0132557

Pai M (2020) Covidization of research: what are the risks? Nat Med 26:1159-1159

Palayew A, Norgaard O, Safreed-Harmon K, Andersen TH, Rasmussen LN, Lazarus JV (2020) Pandemic publishing poses a new COVID-19 challenge. Nat Hum Behav 4:666-669

Pennisi E (2020) Pandemic robs field scientists of 'once-in-a-lifetime' moments. Science. Accessed 14 Nov 2020. https://www.science.org/news/2020/04/ pandemic-robs-field-scientists-once-lifetime-moments

R Core Development Team (2020) R: a language and environment for statistical computing. Foundation for Statistical Computing, Vienna, Austria

Rutz C, Loretto M-C, Bates AE, Davidson SC, Duarte CM, Jetz W, Johnson M, Kato A, Kays R, Mueller T, Primack RB, Ropert-Coudert Y, Tucker MA,
Wikelski M, Cagnacci F (2020) COVID-19 lockdown allows researchers to quantify the effects of human activity on wildlife. Nat Ecol Evol 4:1156-1159

Salerno PE, Páez-Vacas M, Guayasamin JM, Stynoski JL (2020) Correction: Male principal investigators (almost) dont publish with women in ecology and zoology. PLoS ONE 15:e0233803

Santos M, Machado L, Perlin M, Soletti RC, Rosa e Silva LK, Schwartz IVD, Seixas A, Ricachenevsky FK, Neis AT, Staniscuaski F (2019). Parent in science: the impact of parenthood on the scientific career in Brazil. In: IEEE/ACM 2nd international workshop on Gender Equality in Software Engineering (GE), Montreal, QC, Canada. pp. 37-40. https://ieeexplore.ieee.org/document/8819567

Sebo P, Fournier JP, Ragot C, Gorioux P-H, Herrmann FR, Maisonneuve H (2019) Factors associated with publication speed in general medical journals: a retrospective study of bibliometric data. Scientometrics 119:1037-1058

Squazzoni F, Bravo G, Grimaldo F, Garcia-Costa D, Farjam M, Mehmani B (2020) No tickets for women in the COVID-19 race? A study on manuscript submissions and reviews in 2347 Elsevier journals during the pandemic. SSRN Electron J. https://doi.org/10.2139/ssrn.3712813

Squazzoni F, Bravo G, Farjam M, Marusic A, Mehmani B, Willis M, Birukou A, Dondio P, Grimaldo F (2021) Peer review and gender bias: a study on 145 scholarly journals. Sci Adv 7:eabd0299

Stokstad E (2020) Pandemic lockdown stirs up ecological research. Science 369:893-893 Tiokhin L, Yan M, Morgan TJH (2021) Competition for priority harms the reliability of science, but reforms can help. Nat Hum Behav 5:857-867

Tort ABL, Targino ZH, Amaral OB (2012) Rising publication delays inflate journal impact factors. PLoS ONE 7:e53374

Vardi R, Berger-Tal O, Roll U (2021) iNaturalist insights illuminate COVID-19 effects on large mammals in urban centers. Biol Conserv 254:108953

Viglione G (2020) Are women publishing less during the pandemic? Heres what the data say. Nature 581:365-366

Wang P, Chen K, Zhu S, Wang P, Zhang H (2020) Severe air pollution events not avoided by reduced anthropogenic activities during COVID-19 outbreak. Resour Conserv Recycl 158:104814

Ware M, Mabe M (2015) The STM report: an overview of scientific and scholarly journal publishing. International Association of Scientific, Technical and Medical Publishers, The Hague

Yu G, Wang X-H, Yu D-R (2005) The influence of publication delays on impact factors. Scientometrics 64:235-246

\section{Acknowledgements}

We thank Marcos Peso for helping with data collection and Charbel Nino El Hani, Karen Mustin Carvalho and Rehan Ul Haq for comments on a previous version of the manuscript. We also would like to thank Ding-Li Yong for identifying the gender of Chinese and Taiwanese authors.

\section{Competing interests}

The authors declare no competing interests.

\section{Additional information}

Supplementary information The online version contains supplementary material available at https://doi.org/10.1057/s41599-021-00920-9.

Correspondence and requests for materials should be addressed to Lucas Rodriguez Forti.

Reprints and permission information is available at http://www.nature.com/reprints

Publisher's note Springer Nature remains neutral with regard to jurisdictional claims in published maps and institutional affiliations.

Open Access This article is licensed under a Creative Commons Attribution 4.0 International License, which permits use, sharing, adaptation, distribution and reproduction in any medium or format, as long as you give appropriate credit to the original author(s) and the source, provide a link to the Creative Commons license, and indicate if changes were made. The images or other third party material in this article are included in the article's Creative Commons license, unles indicated otherwise in a credit line to the material. If material is not included in the article's Creative Commons license and your intended use is not permitted by statutory regulation or exceeds the permitted use, you will need to obtain permission directly from the copyright holder. To view a copy of this license, visit http://creativecommons.org/ licenses/by/4.0/.

(C) The Author(s) 2021 